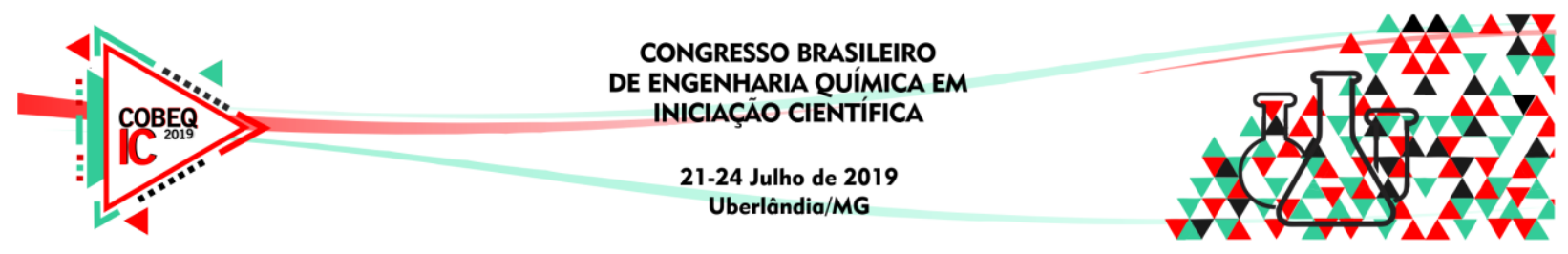

\title{
DESIGN EXPERIMENTAL PARA OTIMIZAÇÃO DA PRODUÇÃO DE LIPASE UTILIZANDO ASPERGILLUS SP.
}

\author{
T. M. SOUZA ${ }^{1}$, J. S. FONSECA ${ }^{2}$ e R.L. SERUDO ${ }^{1,2}$ \\ ${ }^{1}$ Universidade do Estado do Amazonas, Departamento de Engenharia Química \\ ${ }^{2} \mathrm{Hub}$ - Tecnologia e Inovação, Laboratório Ilum \\ E-mail para contato: tmds.eng16@uea.edu.br
}

\begin{abstract}
RESUMO - As lipases são enzimas que catalisam a hidrólise e síntese de triacilgliceróis, gerando matéria-prima para a obtenção de produtos e processos de alto valor comercial. Estas são geradoras de matéria-prima para a obtenção de produtos e processos de alto valor comercial. Dessa forma, o fungo Aspergillus sp., considerado ótimo produtor da enzima, foi submetido à fermentação submersa para produção de lipase. Para este estudo foi elaborado um delineamento composto central $2^{3}$ para análise das variáveis, como: $\mathrm{pH}$, concentração de substrato (\%) e tempo (dias), que podem influenciar o processo. Portanto, a maior atividade específica foi $117.29 \mathrm{U} / \mathrm{mg}$ nas condições de $25^{\circ} \mathrm{C}, \mathrm{pH} 11$, concentração de substrato $15 \%$, agitação de $150 \mathrm{rpm}$ e tempo de 7.32 dias. O fator mais significativo foi o tempo, em seguida a interação entre $\mathrm{pH}$ e óleo e a interação entre pH e tempo. Além disso, o modelo explicou $60 \%$ dos fenômenos, onde uma equação matemática foi obtida para descrever a produção enzimática com as variáveis estudadas.
\end{abstract}

\section{INTRODUÇÃO}

As tecnologias enzimáticas tornaram-se um campo promissor para obtenção de composto de alto valor agregado devido ao uso de tecnologias mais limpas e uso de matériasprimas renováveis. Assim, as lipases passaram a ter um enfoque maior pelo fato de serem solúveis em água, entretanto, catalisam reações que têm substratos lipofílicos (Dos Santos, 2012; Fernandes, 2007; Monteiro e Silva, 2009).

As lipases são enzimas que catalisam a hidrólise de triacilgliceróis liberando ácidos graxos livres, diacilgliceróis, monoacilgliceróis e glicerol. Por terem uma afinidade com diversos substratos, estabilidade em diferentes faixas de temperatura, $\mathrm{pH}$ e solventes orgânicos, possuem aplicação biotecnológica em uma ampla gama de setores, como: indústria farmacêutica, cosméticos, tratamento de efluentes e alimentícia (Carvalho et al., 2005; Castro et al., 2004; Gupta, 2006).

O custo para uso destas enzimas na indústria é exorbitante, onde os preços de venda chegam a $\mathrm{R} \$ 2000,00$, em média, uma grama. Isso deve-se às condições específicas de produção para cada processo. Para minimizar os gastos, é necessário investir em tecnologias, como: equipamentos e processos otimizados, utilizando ferramentas estatísticas (Matias et al., 2005; Messias et al., 2011). 


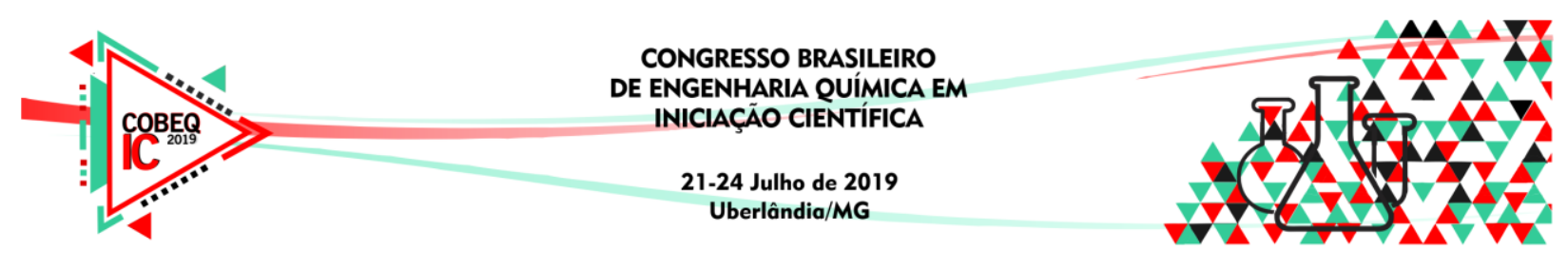

O presente estudo tem como objetivo analisar a produção de lipase extracelular utilizando o fungo Aspergillus sp. e como substrato o óleo doméstico residual, e assim, tornando-se uma alternativa para redução dos custos produtivos. Através do delineamento composto central $2^{3}$ utilizando o software Statistica v.12, buscou-se avaliar as variáveis que podem influenciar a produção como: temperatura $\left({ }^{\circ} \mathrm{C}\right), \mathrm{pH}$ e concentração de substrato $(\%)$.

\section{MATERIAL E MÉTODO}

\subsection{Microorganismo e preparo do inóculo}

O fungo Aspergillus sp. utilizado neste estudo foi adquirido na micoteca do Laboratório ILUM do Hub - Tecnologia e Inovação na Escola Superior de Tecnologia da Universidade do Estado do Amazonas, onde foi desenvolvido o projeto. Para efeito de cultivo e reativação, foi inoculado $50 \mu \mathrm{L}$ da água com esporos do fungo em meio de batata (BDA) (200g de batata, $20 \mathrm{~g}$ de dextrose, $15 \mathrm{~g}$ de ágar em $1 \mathrm{~L}$ de água destilada) e incubado à $30^{\circ} \mathrm{C}$ por 7 dias. Após reativação, o fungo foi inoculado em tubo falcon contendo meio de batata (BDA) à $30^{\circ} \mathrm{C}$ por 3 dias para posterior coleta dos esporos. Foi adicionado $1 \mathrm{~mL}$ de água destilada autoclavada no tubo e raspou-se suavemente para favorecer a suspensão de esporos, e então, foi transferida para erlenmeyer de $125 \mathrm{~mL}$ contendo porcentagem de substrato em relação ao volume $(50 \mathrm{~mL})$ de acordo com delineamento composto central $2^{3}$ gerado no software Statistica v. 12 e o restante meio mínimo de Manachini ( $2 \mathrm{~g}$ de $\mathrm{KH}_{2} \mathrm{PO}_{4}, 1 \mathrm{~g}$ de $\left(\mathrm{NH}_{4}\right)_{2} \mathrm{SO}_{4}, 0.1 \mathrm{~g}$ de $\mathrm{MgSO}_{4} .7 \mathrm{H}_{2} \mathrm{O}, 0.9 \mathrm{~g}$ de $\mathrm{NaHPO}_{4} \cdot \mathrm{H}_{2} \mathrm{O}, 1 \mathrm{~g}$ de Extrato de levedura em 1L de tampão) com pH também obtido no delineamento.

\section{2 Fonte de carbono}

Como indutor de fonte de carbono para a produção de lipase, foi utilizado óleo de fritura residual de soja em residências de parceiros do projeto usuários da marca de óleo Soya. O tempo de fritura estimado é de 15 minutos e foi utilizado para fritar banana a $100^{\circ} \mathrm{C}$.

\subsection{Design experimental para produção de lipase}

Usando o Composto Central $2^{3}$ gerado no software Statistica, observou-se a influência do tempo (8 - 10 dias), pH (9 - 11), e concentração da fonte de carbono (10 - 20\%) no volume total do meio em diferentes níveis $(-1.682,-1,0,+1,+1.682)$, com temperatura fixa de $25^{\circ} \mathrm{C}$ e agitação 150 rpm, obtendo como resposta a atividade específica de lipase (U/mg).

\subsection{Determinação quantitativa de atividade lipolítica}

A dosagem foi realizada para análise da amostra de acordo com a metodologia descrita por (HENRY, 1957; ROE, 1963; WILLIAMSON, 1975) utilizando kit colorimétrico para lipase da marca In Vitro. Foi colocado em microplaca $50 \mu \mathrm{L}$ de solução tampão Tris $0.1 \mathrm{~mol} / \mathrm{L}, 2.5 \mu \mathrm{L}$ de amostra, $2 \mu \mathrm{L}$ de inibidor (fenil-metil-sulfonil fluoreto $20 \mathrm{mmol} / \mathrm{L}$ em etanol), e $5 \mu \mathrm{L}$ de reagente de cor. Depois disso, a amostra foi aquecida no monobloco por 2 minutos a $37^{\circ}$. Em seguida, foi adicionado $5 \mu \mathrm{L}$ de substrato (BALB $20 \mathrm{mmol} / \mathrm{L}$ ) e aquecidos no monobloco por 


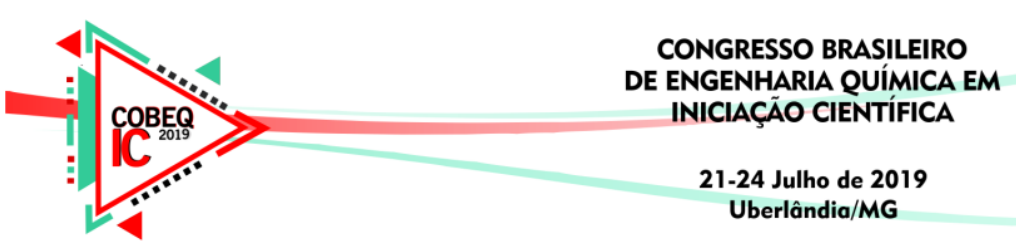

30 minutos a $37^{\circ} \mathrm{C}$.Após esse período, foi adicionado $100 \mu \mathrm{L}$ de inativador (Lauril sulfato de sódio $27.6 \mathrm{mmol} / \mathrm{L}$ ) nas análises da amostra. $\mathrm{O}$ branco foi composto por $64.5 \mu \mathrm{L}$, incubado por 30 minutos a $37^{\circ} \mathrm{C}$, e $100 \mu \mathrm{L}$ de inativador. A leitura foi feita a $410 \mathrm{~nm}$ no Espectrofotômetro da marca Shenzhen Mindray Bio-Medical Eletronics Co., LTD. modelo MR-96A.

\subsection{Dosagem de proteínas (Bradford, 1976 adaptado)}

A dosagem foi feita usando $18.3 \mu \mathrm{L}$ de água destilada, $15 \mu \mathrm{L}$ do extrato enzimático e 266.6 $\mu \mathrm{L}$ do reagente de Bradford por cinco minutos a temperatura ambiente. A leitura no espectrofotômetro marca Shimadzu UV-1800 foi realizada com comprimento de onda de $595 \mathrm{~nm}$. O branco foi feito usando $33.3 \mu \mathrm{L}$ de água destilada e $266.6 \mu \mathrm{L}$ do reagente de Bradford.

\subsection{Análise estatística}

Os resultados foram analisados no Statistica versão 12.0 para a geração de gráficos de superfície e modelo matemático, além da análise variância (ANOVA) com $\mathrm{p}=0.05$. Além disto, também foi realizado o Teste $\mathrm{F}$ para averiguar a qualidade do modelo gerado.

\section{RESULTADOS E DISCUSSÃO}

A partir de resultados obtidos em um planejamento experimental anterior, propôs-se um novo delineamento composto central para avaliar os efeitos do $\mathrm{pH}$, tempo (dias) e concentração de óleo (\%), que foram as variáveis significativas no planejamento anterior. Assim, a matriz do delineamento e resultados obtidos de atividade específica U/mg seguem abaixo na tabela 1.

Tabela 1 - Atividade específica nos parâmetros do composto central $2^{3}$

\begin{tabular}{|c|c|c|c|c|c|c|}
\hline Teste & $\mathbf{p H}$ & $\begin{array}{c}\text { Tempo } \\
(\mathbf{d i a s})\end{array}$ & $\begin{array}{c}\text { Óleo } \\
(\mathbf{\%})\end{array}$ & $\begin{array}{c}\text { Atividade } \\
\text { lipolítica (U/mL) }\end{array}$ & $\begin{array}{c}\text { Proteína } \\
(\mathbf{m g} / \mathbf{m L})\end{array}$ & $\begin{array}{c}\text { Atividade } \\
\text { específica } \\
\text { (U/mg) }\end{array}$ \\
\hline $\mathbf{1}$ & 10 & 8 & 10 & 157.715 & 15.071 & 10.46 \\
\hline $\mathbf{2}$ & 10 & 8 & 20 & 361.876 & 10.926 & 33.12 \\
\hline $\mathbf{3}$ & 10 & 10 & 10 & 137.885 & 36.026 & 3.83 \\
\hline $\mathbf{4}$ & 10 & 10 & 20 & 421.364 & 16.111 & 26.15 \\
\hline $\mathbf{5}$ & 12 & 8 & 10 & 262.588 & 26.553 & 9.89 \\
\hline $\mathbf{6}$ & 12 & 8 & 20 & 157.017 & 16.900 & 9.29 \\
\hline $\mathbf{7}$ & 12 & 10 & 10 & 686.969 & 16.900 & 40.65 \\
\hline $\mathbf{8}$ & 12 & 10 & 20 & 567.154 & 23.413 & 24.22 \\
\hline $\mathbf{9}$ & 9.32 & 9 & 15 & 304.063 & 8.360 & 36.37 \\
\hline $\mathbf{1 0}$ & 12.68 & 9 & 15 & 154.084 & 14.640 & 10.52 \\
\hline $\mathbf{1 1}$ & 11 & 7.32 & 15 & 524.003 & 4.467 & 117.29 \\
\hline $\mathbf{1 2}$ & 11 & 10.68 & 15 & 319.144 & 9.329 & 34.21 \\
\hline $\mathbf{1 3}$ & 11 & 9 & 6.59 & 343.024 & 17.187 & 19.96 \\
\hline $\mathbf{1 4}$ & 11 & 9 & 23.41 & 315.374 & 23.611 & 13.36 \\
\hline $\mathbf{1 5}(\mathbf{C})$ & 11 & 9 & 15 & 269.151 & 17.116 & 15.73 \\
\hline $\mathbf{1 6}(\mathbf{C})$ & 11 & 9 & 15 & 489.232 & 18.623 & 26.27 \\
\hline $\mathbf{1 7}(\mathbf{C})$ & 11 & 9 & 15 & 319.563 & 21.852 & 14.62 \\
\hline $\mathbf{1 8}(\mathbf{C})$ & 11 & 9 & 15 & 243.736 & 21.278 & 11.45 \\
\hline
\end{tabular}




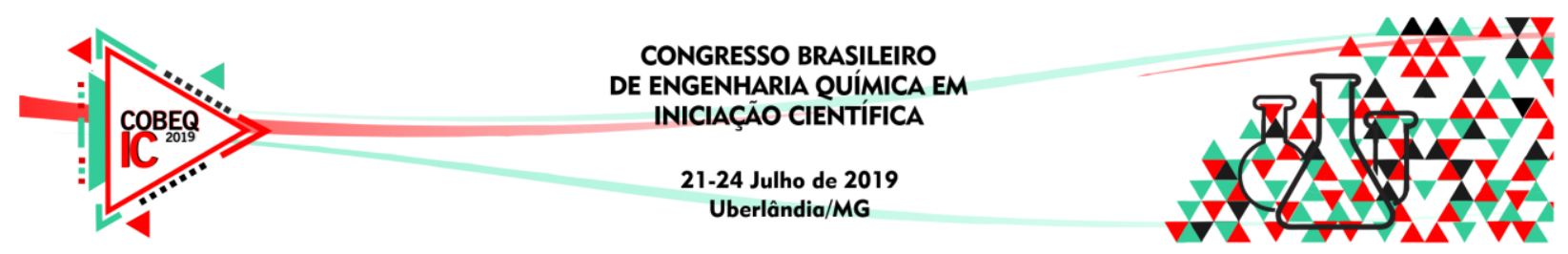

O teste 11 apresentou a maior atividade específica de $117.29 \mathrm{U} / \mathrm{mg}$. Este valor se mostra superior comparado com Lima et al. (2004) que em meio contendo fonte de nitrogênio de baixo custo obteve $111 \mathrm{U} / \mathrm{mg}$, com Fernandes (2007) que obteve $59 \mathrm{U} / \mathrm{mg}$ do extrato bruto utilizando Burkholderia cepacia cultivada em fermentação sólida e a lipase bruta de Geotrichum candidum comercializada pela Amano Pharmaceutical Co (GC-4), Japão, que apresenta atividade específica de $80 \mathrm{U} / \mathrm{mg}$, conforme Carvalho et al. (2005).

Ademais, o teste 3 apresentou a menor atividade específica de $3.83 \mathrm{U} / \mathrm{mg}$, mas se mostra superior em comparação com Razak (1996) que obteve 1.2 e $1.14 \mathrm{U} / \mathrm{mg}$ utilizando Rhizopus oryaze, com Colen et al. (2006) que obteve $2.7 \mathrm{U} / \mathrm{mg}$ ao fermentar C.gloesporiodes por $96 \mathrm{~h}$ e com Carvalho et al. (2005) que obteve $0.56 \mathrm{U} / \mathrm{mg}$.

A partir do gráfico de Pareto (Figura 1) verificou-se que o tempo, tanto em relação ao efeito linear quanto quadrático, foi a variável de maior significância para a atividade lipásica ao nível de confiança (95\%) em relação ao grau de liberdade. O tempo (L) tem um efeito negativo, indicando que com a diminuição do tempo, a produção enzimática aumenta. Entretanto, como o tempo (Q) tem efeito positivo, existe um certo nível limitante para melhoramento da resposta. Ademais, a interação entre $\mathrm{pH}(\mathrm{L})$ e óleo(L) e a interação entre $\mathrm{pH}(\mathrm{L})$ e tempo(L) se mostraram significativas para o processo.

Figura 1 - Gráfico de Pareto dos testes do composto central $2^{3}$.

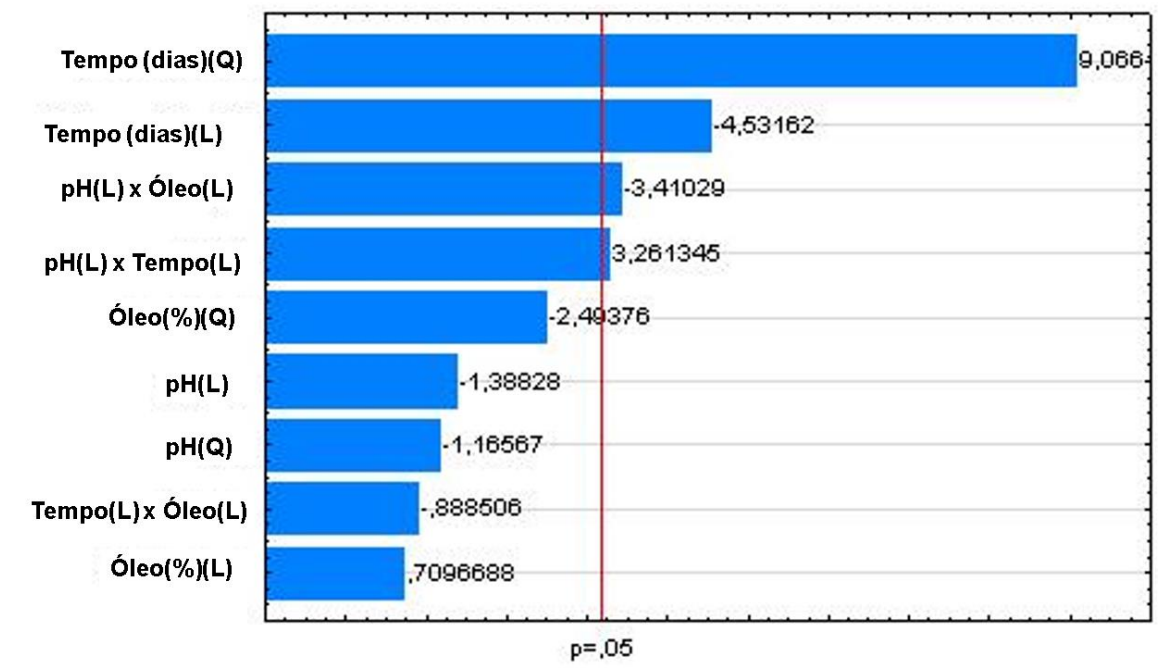

Foi possível explicar cerca de $60 \%$ dos fenômenos que ocorre durante a produção lipásica com a possibilidade de alcançar $98.76 \%$, se corrigidos os ajustes de acordo com a ANOVA. Para validar o modelo, empregou-se o teste F, que é usado para medir a precisão. Os valores obtidos do Teste $\mathrm{F}$ em relação à regressão e à falta de ajuste estão representados nas equações 1 e 2 abaixo.

$$
\frac{\text { Média quadrática da regressão }}{\text { Média quadrática resíduo }}=19.69>4.49=\mathrm{F}_{1,16}
$$




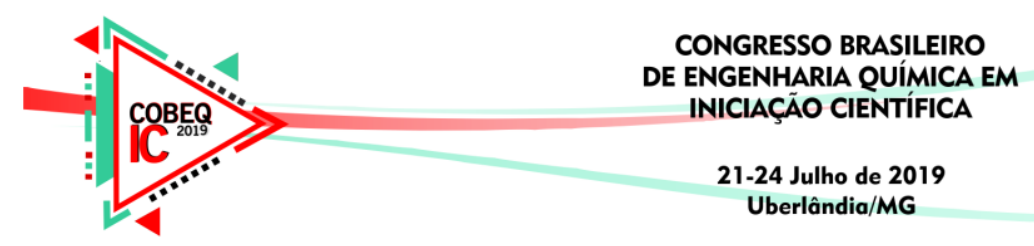

$$
\frac{\text { Média quadrática devido a falta de ajuste }}{\text { Média quadrática erro experimental }}=536.54>4.54=\mathrm{F}_{1,15}
$$

Pelo fato de a regressão ser significativa (equação 1), há uma relação entre as variáveis estudadas para compor o modelo quadrático e as variáveis externas pouco alteram o sistema. Através do ajuste e erros (equação 2) foi possível mostrar a possibilidade de melhorar o modelo de estudo. Assim, obteve-se um modelo matemático que descreve o comportamento da atividade específica em função do $\mathrm{pH}$, tempo e concentração do substrato, conforme equação 3. Atividade específica $\left(\frac{U}{m g}\right)=17.99-2.41 p H-7.88$ tempo +1.23 substrato -
$2.1 p H^{2}+16.38$ tempo ${ }^{2}-4.5$ óleo $^{2}+7.41 p H$ tempo $-7.75 p H o ́ l e o-2.02$ tempoóleo

Por meio das superfícies de resposta (Figura 2), verificou-se uma tendência de maior atividade lipásica quando empregada as condições de maior concentração do substrato e menor $\mathrm{pH}$, assim como, maior tempo e maior $\mathrm{pH}$ ou menor tempo e menor $\mathrm{pH}$.

Figura 2 - Superfície de resposta de atividade enzimática de lipase em diferentes faixas de $\mathrm{pH}$ e concentração de substrato (\%) produzida por Aspergillus sp. em $150 \mathrm{rpm}$ e $25^{\circ} \mathrm{C} \mathrm{em}$

A) 7 dias e em B) $10 \%$ de óleo (substrato).
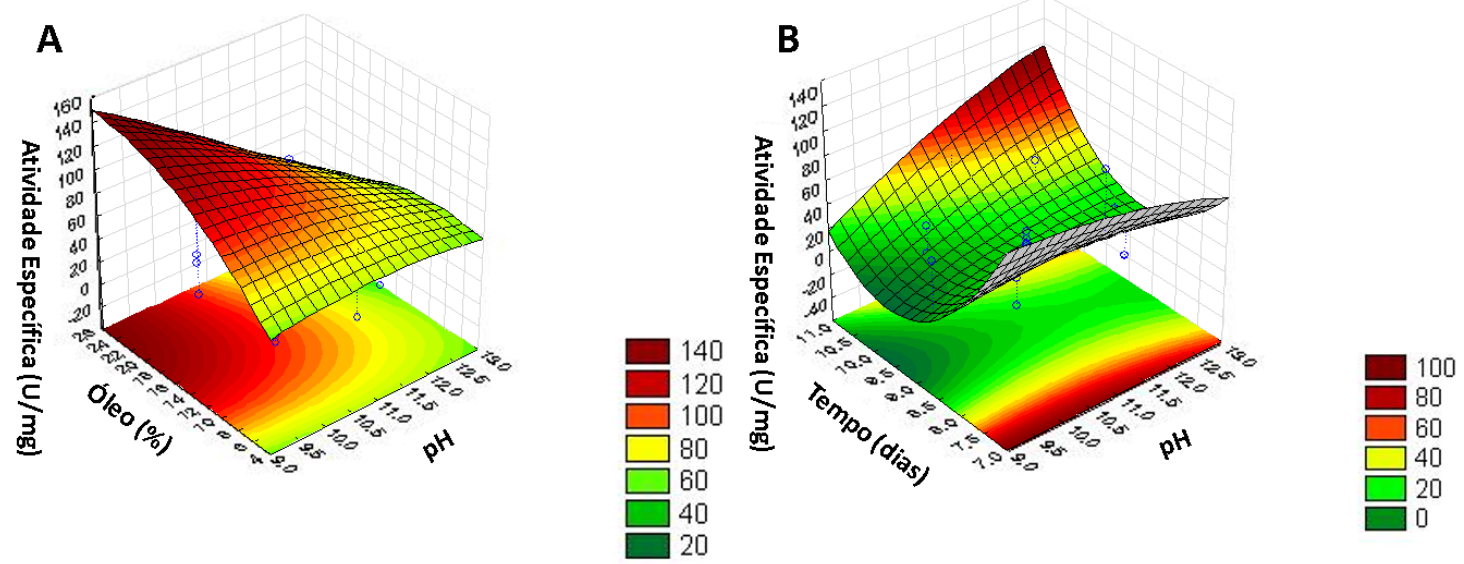

De acordo com figura $2 \mathrm{a}$, quando o $\mathrm{pH}$ diminui, a concentração de substrato que pode ser aplicada no processo fermentativo aumenta. Em 7 dias, pH 9 e 24-26\% de óleo, pode-se obter $140 \mathrm{U} / \mathrm{mg}$ de atividade específica. Na figura 2b, ao reduzir o tempo (dias) e o $\mathrm{pH}$, ou ao aumentar o tempo (dias) e o $\mathrm{pH}$, a atividade específica aumenta devido a interação significativa entre essas duas variáveis, de acordo com a figura 1. Assim, em 7 dias (ou 11dias), pH 9 (ou $\mathrm{pH} 12)$ e $10 \%$ de substrato, a atividade específica é de $100 \mathrm{U} / \mathrm{mg}$.

Portanto, para otimizar a atividade lipásica, as melhores faixas de $\mathrm{pH}$ devem estar entre 9-12 e a concentração do substrato entre 10-26\%. Além disso, deve-se continuar utilizando temperaturas em torno de $25^{\circ} \mathrm{C}$ para não ocorrer desnaturação enzimática (Murray et al., 2003) e agitação próxima de $150 \mathrm{rpm}$ para melhor biodisponibilidade dos nutrientes, conforme Cihangir e Sarikaya (2004). 


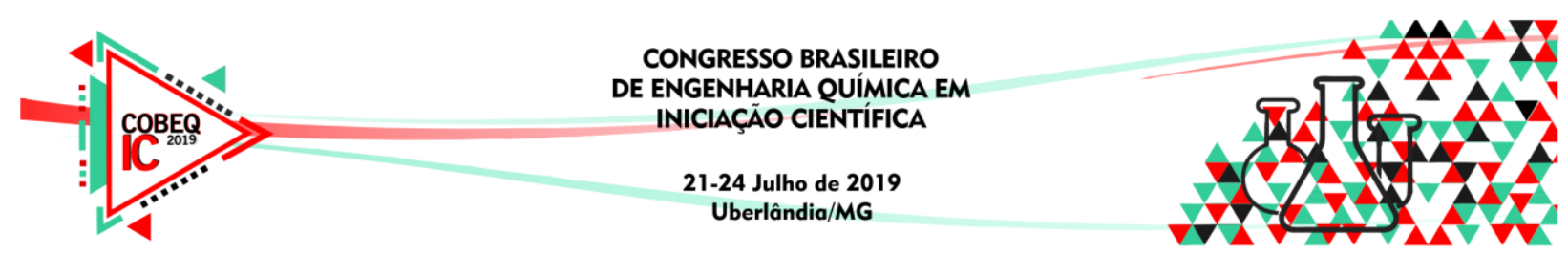

\section{CONCLUSÃO}

Os resultados obtidos determinaram que o tempo (L) de fermentação e a interação entre $\mathrm{pH}(\mathrm{L})$ e óleo(L) tem efeito negativo resultando na máxima produção de lipase pelo fungo Aspergillus sp. em fermentação submersa. Ademais, quando a interação entre $\mathrm{pH}(\mathrm{L})$ e tempo(L) aumenta, a atividade também aumenta. Assim, a condição ideal deve ser obtida ao utilizar o pH próximo de 9 ou 12, tempo em torno de 7 ou 11 dias, concentração de substrato entre 10-26\% e permanecendo com $25^{\circ} \mathrm{C}$ e $150 \mathrm{rpm}$. Além disso, pôde-se obter uma visão geral da estimativa de efeitos e ANOVA, sendo explicado $60 \%$ dos fenômenos e havendo a necessidade de melhorar o modelo de estudo.

\section{REFERÊNCIAS}

BRADFORD, M. M. A rapid and sensitive method for the quantitation of microgram quantities of protein utilizing the principle of protein-dye binding. Anal. Biochem., v. 72, p. 248, 1976.

CARVALHO, P. O.; CALAFATTI, S. A.; MARASSI, M.; SILVA, D. M.; CONTESINI, F. J.; BIZACO, R. Potencial de biocatálise enantiosseletiva de lipases microbianas. Química Nova, v. 28, n. 4, p. 614-621, 2005.

CIHANGIR, N.; SARIKAYA, E. Investigation of lipase production by a new isolate of Aspergillussp. World Journal of Microbiology \& Biotechnology, v. 20, n. 2, p. 193-97, 2004. CASTRO, H. F.; MENDES, A.A.; SANTOS, C. J. Modificação de óleos e gorduras por biotransformação. Química Nova, v. 27, n. 1, p. 146-156, 2004.

COLEN, Gecernir; JUNQUEIRA, Roberto Gonçalves; MORAES-SANTOS, Tasso. Isolation and screening of alkaline lipase-producing fungi from Brazilian savanna soil. World Journal of Microbiology and Biotechnology, v. 22, n. 8, p. 881-885, 2006.

DOS SANTOS, R. R. Caracterização e aplicação de borras do refino de óleos vegetais para produção de lipase fúngica por fermentação no estado sólido. Embrapa Agroenergia-Outras publicações científicas (ALICE), 2012.

FERNANDES, M. L. M. Produção de lipases por fermentação no estado sólido e sua utilização em biocatálise. Tese (Doutorado em química). Universidade Federal do Paraná, 2007.

LIMA, Valéria MG et al. Evaluation of the potential for use in biocatalysis of a lipase from a wild strain of Bacillus megaterium. Journal of Molecular Catalysis B: Enzymatic, v. 31, n. 13, p. 53-61, 2004.

MATIAS, E., PIMENTEL, N. Biotecnologia: Um desafio para o Amazonas. Parcerias Estratégicas, v. 21, n.1, 2005.

MESSIAS, J. M.; COSTA, B. Z.; LIMA, V. M. G.; GIESE, E. C.; DEKKER, R. F. H.; BARBOSA, A. M. Lipases microbianas: Produção, propriedades e aplicações biotecnológicas. Semina: Ciências Exatas e Tecnológicas, Londrina, v. 32, n. 2, p. 213- 234, 2011.

MONTEIRO V. N., SILVA R. N. Aplicações Industriais da Tecnologia Enzimática. Processos Químicos. Goiânia: SENAI/DR, v.3, n.5, ano 3, p.10-23, jan/jun 2009.

MURRAY, P. R.; BARON, E. J.; PFALLER, M. A.; TENOVER, F. C.; YOLKEN, R. H. M. Manual of clinical microbiology. 8. ed. Washington: ASM Press, p. 2113, 2003.

RAZAK, C. N. A. et al. Some characteristics of lipases from thermophilic fungi isolated from palm oil mill effluent. Journal of Molecular Catalysis B: Enzymatic, v. 3, n. 1-4, p. 153-159, 1997. 